\title{
IDENTIFIKACIJA GASTRONOMSKIH RESURSA KAO DELA KULTURNOG NASLEĐA U RAZRADI KONCEPTA ODRŽIVOG RAZVOJA VOJVODINE
}

\author{
Dragan Tešanović, \\ Maja Banjac, \\ Bojana Kalenjuk, \\ Predrag Tošić
}

Univerzitet u Novom Sadu, Prirodno-matematički fakultet, Departman za geografiju, turizam i hotelijerstvo,

Novi Sad, Srbija
Correspondence:

Dragan Tešanović

e-mail:

dragan.tesanovic@dgt.uns.ac.rs

\begin{abstract}
Rezime:
Turistička delatnost u severnoj pokrajini Republike Srbije beleži trend rasta. Njen razvoj se uglavnom sagledava po ostvarenom broju noćenja dok je učešće pojedinih subjekata koji sudeluju u kreiranju turističkog proizvoda kao što je lokalna poljoprivreda i restoraterstvo su manje vidljivi. To uslovljava da zajednica i nadležni državni subjekti svojim delovanjem nedovoljno podstiču proizvodnju i upotrebu lokalne hrane, iako ona predstavlja oblik kulturnog kapitala i resurs ekonomsko-socijalnog razvoja. Mesto istraživanja je AP Vojvodina. Predmet rada je lokalna hrana u turističkoj ponudi regiona. Zadatak rada je da se primenom Rinaldijevog modela utvrdi da li postoje svi aspekti identiteta lokalne hrane u zajednici koji su značajni za kreiranje koncepta održivog turizma. Cilj rada je da se sa identifikacijom postojećih gastronomskih resursa sagleda i istakne njihov potencijal kao i značaj u razvoju regiona. Istraživanje je pokazalo da Vojvodina poseduje sva četiri identifikovana lokalna resursa ali da se oni u cilju razvoja turizma nedovoljno koriste. Razrada koncepta održivog turizma nije dovoljno prepoznata u razvoju regiona.
\end{abstract}

Ključne reči:

lokalna hrana, identifikacija resursa, održivi turizam

UVOD

Hrana i gastronomija daju znatan doprinos održivosti regiona. Najznačajniji lokalni resursi na kojima se temelji razvoj svrstani su u dve dimenzije: podneblje i ljudi. Određeno podneblje sagledava se i po ekonomskim karakteristikama u kom značajan prostor zauzima lokalna poljoprivreda, odnosno hrana (Rinaldi, 2017). Ona svojom jedinstvenošću pozitivno utiče na formiranje gastronomske kulture i tradicije što doprinosi autentičnosti i prepoznatljivosti mesta (Waligo et al., 2013). Prehrambene navike koje potiču iz jedne kulture su pod uticajem socijalnog, kulturnog i verskog nasleđa (McIntosh, 1995). Podneblje daje jedinstvene karakteristike hrani i zato se smatra važnom karikom u ostvarenju održivog razvoja (Branvell and Ravding, 1996) i kulturnog nasleđa destinacije.

Dimenzija ljudi opisuje se kao zajednica kojoj pripadaju različite vrste zanimanja: poljoprivrednici, proizvođači hrane, prerađivači hrane, kuvari, turistički planeri, vlast, domicilno stanovništvo. Svi oni 
neguju lokalne običaje i nasleđe koje predstavlja izvor identiteta i koje doprinosi autentičnosti i održivom razvoju mesta. Povezivanja hrane, mesta i ljudi je važan zadatak kreatora razvojne politike. Ove tri dimenzije se smatraju značajnim za obezbeđivanje održivog razvoja turizma (Kavaratzis et al., 2013; Vandecandelaere et al., 2009) i negovanje tradicije i kulture. Cilj održivog razvoja je korist i zadovoljstvo svih učesnika u lancu (Polocck, 2015). U slučaju da fokus bude samo na nekoliko aktera može doći do narušavanja i gubitka lokalnog kvaliteta i vrednosti (Dvier, 2017).

Predmet rada je tradicionalna hrana kao kulturni i ekonomski resurs u razradi koncepta održivog turizma. Zadatak rada je da se primenom Rinaldijevog modela utvrdi da li postoje kulturni i svi drugi aspekti identiteta gastronomije lokalne zajednice, koji su značajni za kreiranje koncepta održivog turizma. Cilj rada je da se identifikacijom hrane kao kulturnog nasleđa postojećih resursa sagleda i istakne njihov turistički potencijal kao i značaj u održivom razvoju regiona.

\section{METODOLOGIJARADA}

Istraživanje je sprovedeno na teritoriji AP Vojvodina. U cilju što kvalitetnije obrade podataka istraživanje je podeljeno u dve etape. U prvom delu izvršeno je prikupljanje podataka za stolom. Analizirane su dostupne studije koje su rađene u svetu na temu razrade koncepta održivog turizma gde je kao jedan od katalizatora razvoja regiona gastronomija. Pored toga sagledavane su dostupne studije i strategije razvoja AP Vojvodina. Drugi deo istraživanja vezuje se za identifikovanje postojećih gastronomskih resursa, kao kulturnog nasleđa, u cilju razvoja koncepta održivog turizma. Sagledavanje je izvršeno po uzoru na model koji je kreirala Rinaldi (2017). Kreirani model baziran je na identifikaciji četiri resursa (teritorijalne prirodne karakteristike i pejzaž, lokalna mesta za proizvodnju i konzumaciju hrane, lokalni sistemi za distribuciju hrane, manifestacije hrane) koje prate tri dimenzije (mesto, ljudi i kulturno nasleđe). Resursi i dimenzije poseduju opisne karakteristike koje su neophodne u razvoju koncepta održivog turizma. Studije i radovi rađeni u Vojvodini ukazuju da karakteristike ljudi koji su na direktan ili indirektan način uključeni u turistički sektor su u malom broju sagledavane. To je uticalo da i u ovome radu opisne karakteristike ljudi koje propisuje navedeni model nisu obrađivane.

\section{REZULTATI RADA I DISKUSIJA}

Rogerson (2012) ističe da studije koje se bave turističkim strategijama razvoja uglavnom se fokusiraju na povećani broj posetilaca dok se programi planiranja međusektorske saradnje koja pospešuje povećanje broja turista zanemaruje. Strategija razvoja turizma Republike Srbije za period 2016. - 2025. potvrđuje navedenu konstataciju. Ona na prvom mestu navodi da ugostiteljski sektor ima direktne efekte na razvoj turizma, dok se plasman poljoprivrednih proizvoda smatra indirektnim faktorom i to bez isticanja značaja lokalne, tradicionalne poljoprivrede, prehrambene industrije i gastronomije. Iz navedenog se uočava da Vlada svojim delovanjem nedovoljno podstiče proizvodnju i upotrebu lokalne hrane i proizvoda u turističkoj potrošnji, kao značajnog kulturnog nasleđa.

Izučavajući dostupne teorijske i praktične studije rađene u svetu na temu koncepta održivog turizma regiona došlo se do saznanja da se radi o vrlo kompleksnom modelu čiju razradu je neophodno temeljiti isključivo na postojećim i dostupnim resursima u regionu u kojem se razvija, potencirajući kulturno nasleđe iz svih sfera života. Dwyer (2017) navodi da jedan od nedostataka u ostvarivanju održivog razvoja su široko postavljeni principi na osnovu kojih su prakse neodržive. Koncept održivosti mora da prati međusektorska saradnja (Banjac et al., 2017a). Postojeće modele koji su se pokazali kao dobar nije moguće u potpunosti primeniti oni treba da služe kao smernica u postavci jedinstvenog koncepta iz razloga što ni jedno podneblje nema iste karakteristike i nema istu tradiciju i kulturno nasleđe (Banjac et al., 2017b). Kreiranje i uspostavljanje modela održivog turizma razvija se dugoročno zato se smatra da je dobro koristiti praktična iskustva drugih (Pollock, 2015).

Koncept integrisanog upravljanja u čijem fokusu je sagledavanje socio-političkih, ekonomskih i ekoloških varijabli što bi uslovilo kreiranje pet kapitalnih zona (finansijska, prirodna, društvena, fizička i ljudska),uvažavajući tradiciju, kulturu i autentičnost, unutar kojih bi se kreirali indikatori i ciljevi. Rezultati rada se prate fazno a za procenu učinka koriste se kvalitativne i kvantitativne analize (Cambell, 2001). Kako 
bi se ostvario razvoj važno je i sagledati viđenja turističkih planera, stavove poljoprivrednika i ugostitelja i potencijal destinacije jer između svih subjekata postoje značajni interesi (Getz et al., 2014). Polazna osnova u razradi koncepta održivog turizma je identifikacija resursa, posebno onih koji predstavljaju materijalno i nematerijalno kulturno nasleđe a koja će u predstojećem delu biti prikazana. Svaku opisnu karakteristiku mesta prati opis nakon čega je prikazana trenutna situacija u Vojvodini.

\section{Prvi resurs: Teritorijalne prirodne karakteristike i pejzaž}

\section{Opisne karakteristike mesta:}

Autentična hrana proizlazi iz specifičnih teritorijalnih prirodnih uslova i kulturnog nasleđa sredine. Zemlja određenog područja "teroar" i mikroklima daju karakteristične osobine prehrambenim i gastronomskim proizvodima. Kvalitet zemljišta znatno utiče na kvalitet hrane. Podneblja koja poseduju specifičan teroar doprinose povećanju atraktivnosti mesta (Rinaldi, 2017). Načini uzgoja, prerade, čuvanja i specifične recepture, oprema, posuđe, prostor i niz drugih tradicionalnih elemenata predstavljaju specifičnosti kulture života i ishrane stanovništva, bitnih za stvaranje autentične lokalne gastronomije i interesantne turističke gastro ponude zasnovane na turističkom nasleđu lokalne sredine.

Teritorijalne prirodne karakteristike i pejzaž u Vojvodini:

- Od ukupne površine Vojvodine (2.150.600 ha) poljoprivredno zemljište čini 1.474 .000 ha odnosno $81,26 \%$ dok je učešće obradivog zemljišta 74,6\%. Prema načinu korišćenja zemljišta Vojvodina predstavlja izrazito ratarsku oblast, najzastupljenije su oranice sa udelom od $90 \%$, pašnjaci $6 \%$, livade $2 \%$, voćnjaci $1 \%$ i vinogradi 1\% (Milić, 2011). Prirodni pejzaž u regionu promoviše održivu poljoprivredu i smatra se važnim za turističku aktivnost destinacije što će se direktno odraziti i na životnu sredinu (Banjac et al., 2017b).

- zemljište u Vojvodini po svim svojim svojstvima spada u red prvoklasnog zemljišta u Evropi pa i u svetu (Milić, 2011), što se odražava direktno na kvalitet poljoprivrednih proizvoda;

- Poljoprivredna proizvodnja poslednjih nekoliko godina ostvaruje konstantan porast i broj poljoprivrednih gazdinstava i beleži trend rasta. Značajno je istaći da se 1/4 obradivog zemljišta regiona nalazi u vlasništvu poljoprivrednika (PKV, 2018).

- Manigodić i Manigodić, (2008) ističu da pravna zaštita oznake geografskog porekla predstavlja razvojnu šansu privrede. U Zavodu za intelektualnu svojinu Republike Srbije (www.zis.gov.rs) oznaku geografskog porekla na teritoriji Vojvodine poseduje 13 proizvoda.

- U Srbiji je trenutno na snazi Strategija razvoja poljoprivrede i ruralnih područja (2014 - 2024) gde je stavljen akcenat na zdravstvenu bezbednost proizvoda odnosno na samo jedan aspekt kvaliteta. Cilj Strategije je da se na tržištu do 2024. godine nađu lokalni, tradicionalni proizvodi, kao elementi kulturnog nasleđa, koji ispunjavaju propise Evropske unije. Postavljeni cilj vodi ka indikaciji da se trenutno na tržištu ne nalazi dovoljan broj lokalnih tradicionalnih, proizvoda koji se plasiraju na turističko tržište (Caribbean Tourism Research and Development Centre, 1984).

Opisnu karakteristiku mesto istraživanja u potpunosti poseduje. Vojvodina ima sve predispozicije za plasiranje autentične, lokalne i regionalne tradicionalne ponude, zasnovane na kulturnom nasleđu i prirodnim resursima (Tešanović et al., 2018). Turizam i poljoprivreda regiona imaju potencijal da rade u simbiozi i eksploatišu bogato proizvodno i kulturno nasleđe. Turističke promocije mogu biti bazirane na poljoprivrednim lokalnim proizvodima i pospešiti njihov izvoz, dok se poljoprivredna promocija fokusira na regionalnim pejzažima i uzgoju lokalnih biljnih i životinjskih vrsta (Banjac et al., 2017a).

\section{Drugi resurs: Lokalna mesta za proizvodnju i konzumaciju hrane}

Opisne karakteristike mesta: Koncept u kojem se hrana služi i konzumira predstavlja element brendiranja i doprinosi autentičnosti. Lokalna gastronomija razvija identitet mesta i turisti se upoznaju sa gastronomskom kulturom i tradicijom. Lokalna gastronomija podrazumeva upotrebu proizvoda koji se uzgajaju na istom podneblju gde se i uslužuje hrana (Rinaldi, 2017). 
Lokalna mesta za proizvodnju i konzumaciju hrane u Vojvodini:

- Mesto istraživanja je multikulturalni region u kom je izmešan veliki broj kuhinja. Kultura ishrane je odraz složenih uslova života i uticaja brojnih činilaca kulture hrane koja se razlikuje od sela do sela (Stojanović, Čerović, 2008) što je uslovilo nastanak jedinstvenih mesta za ljubitelje hrane.

- U Vojvodini se nalazi 11 specijalnih rezervata prirode u okviru kojih posluju ugostiteljski objekti. Od njih se ističe Specijalni rezervat prirode Zasavica, koji se nalazi u blizini Sremske Mitrovice, poznat po uzgajanju posebne rase svinja Mangulica, čije meso ima kvalitetan nutritivni sastav, kao i meso magaraca od čijeg mleka se proizvodi možda i najskuplji sir na svetu (1 kg = 1000 evra) (Kalenjuk et al., 2017, www.zis.gov.rs).

- Vinski rejoni i vinogorja po kojima je podneblje poznato smatraju se važnim jer mnoge vinarije poseduju objekte za usluživanje posetilaca (Pivac, 2012).

- Na rečnom toku Dunava od Bezdana do Beške nalazi se više od trideset čardi, koje svojim posetiocima pružaju mogućnost uživanja u vojvođanskim ribljim specijalitetima (Banjac et al., 2016).

- U Vojvodini se nalazi oko 115 lovišta u čijem sastavu su ugostiteljski objekti koji pored smeštaja nude mogućnost uživanja u lovačkim specijalitetima od sitne i krupne divljači, pripremljena na tradicionalan način (Kalenjuk et al., 2018).

- Na teritoriji Vojvodine se nalazi ukupno 65 salaša, koji su iz starih napuštenih seoskih domaćinstava pretvoreni u ugostiteljske objekte za pružanje usluga hrane i pića, pa čak i smeštaja (Božin, 2018), kao deo kulture i tradicije koju sa sobom nosi život u ravnici.

Mesto istraživanja poseduje opisne karakteristike drugog resursa ali je važno istaći sledeće pokazatelje. Podneblje poseduje oazu autentičnih tradicionalnih ugostiteljskih objekata, kao deo materijalnog i nematerijalnog kulturnog nasleđa. Međutim istraživanja koja se vezuju za ponudu hrane i pića u Vojvodini ističu nedovoljan broj autentičnih, tradicionalnih, domaćih jela, u ponudi ugostiteljskih objekata. Istraživanja su pokazala da ponuda hrane nije u dovoljnoj meri lokalna i autentična (Gajić 2008; Kalenjuk et al. 2010; Tešanović et al. 2010, 523; Kalenjuk et al. 2012, 357; Banjac et al. 2016: 504; Tešanović et al. 2016, 169). Istraživanje je izvršeno na uzorku od 10.923 jela u 147 ugostiteljskih objekata (Kalenjuk, 2012). Vuksanović i saradnici potvrđuju navedene konstatacije, jer su turisti koji su boravili u Novom Sadu ocenili da konzumacija nedovoljno autentične hrane negativno utiče na atraktivnost destinacije, dok su kulturu ishrane ocenili kao značajan faktor atraktivnosti. Negativni stavovi turista prema domaćoj hrani nastali su zbog jednolične gastronomske ponude i nepostojanja oznake o lokalnom i autentičnom proizvodu (Vuksanović et al. 2017).

\section{Treći resurs: lokalni sistemi za distribuciju hrane}

Opisne karakteristike mesta: Tradicionalna lokalna hrana, koja se proizvodi, ima značajnu ulogu u razradi koncepta održivog turizma. Važno je sa tržišta isključiti globalne distributere hrane. Proizvodnju hrane treba sagledati kulturološki, ali i socio-geografski gde se domicilna aktivnost ugrađuje u prirodni pejzaž određenog mesta (Rinaldi, 2017).

Lokalni sistemi za distribuciju hrane u Vojvodini

Sagledavajući potencijale prvog resursa za očekivati je da će mesto istraživanja ispunjavati opisne karakteristike, ali trenutna situacija je suprotna. Indikatori na osnovu kojih se došlo do saznanja da mesto istraživanja ne zadovoljava opisne karakteristike su:

- $33 \%$ zaposlenih u ugostiteljstvu je pri stavu da su uvozni proizvodi kvalitetniji od domaćih koji se trenutno nalaze na tržištu.

- Velika fluktuacija zaposlenih u ugostiteljstvu ima negativne posledice po uspostavljanje saradnje i konsolidacije sa lokalnim dobavljačima.

- Nizak stepen obrazovanja zaposlenih u ugostiteljstvu često utiče na formiranje slabe lokalne povezanosti i dominantne upotrebe uvoznih proizvoda i namirnica.

- Odsustvo sposobnosti lokalnih poljoprivrednika da plasiraju svoje proizvode na turističko tržište kao i neposedovanje kapaciteta za snabdevanje ugostiteljskih objekata lokalnim proizvodima. 
- Između poljoprivrednika i ugostitelja nema poverenja, poljoprivrednici navode da ugostitelji često kasne sa isplatom dostavljene robe, dok ugostitelji navode da poljoprivrednici nemaju stalno na lageru namirnice i proizvode koji su im neophodni za poslovanje.

- Na tržištu se nalazi veliki broj inostranih distributivnih centara koji plasiraju često jeftiniju i uvoznu robu (Tešanović et al., 2018; Banjac et al., 2017b).

\section{Četvrti resurs: Manifestacije hrane}

Opisne karakteristike mesta: Festivali hrane doprinose očuvanju i razvoju lokalnog agro-prehrambenog sistema, koji se smatra važnim delom lokalnog identiteta (Rinaldi, 2017) i kulturne tradicije.

Manifestacije hrane u Vojvodini:

- Ukupan broj manifestacija u 2014. godini koje su posvećene isključivo hrani ili piću i manifestacija u kojima su hrana i piće jedan od segmenata događaja iznosi 224, u selima se održalo 135 (Tešanović et al., 2017).

- Najveći broj manifestacija zasnovan je prvenstveno na hrani 51\%, dok je $41 \%$ manifestacija u kojima su hrana ili piće sastavni deo organizacije koja ima različit tematski karakter, najčešće su to etno-festivali (Kalenjuk,et al., 2012a).

- 39\% manifestacija ima takmičarski karakter i to pretežno u pripremanju vojvođanskih nacionalnih jela kao što su riblja čorba, gulaš, paprikaš, pasulj i slično.

- $11 \%$ manifestacija ima izložbeni karakter pri čemu su najzastupljenije izložbe i degustacije domaćih, autohtonih vina, ali i žestokih pića (Tešanović et al., 2017).

- 50\% manifestacija ima različit karakter, pri čemu su hrana i piće sastavni i neizbežni deo dešavanja i ponude koja je zasnovana na domaćim specijalitetima (Kalenjuk,et al., 2012a).

Izučavajući dostupne studije došlo se do saznanja da mesto istraživanja zadovoljava propisane kriterijume. Rezultati o gastronomskom manifestacijama i njihovoj razuđenosti u regiji ukazuju na velik potencijal i težnju ka očuvanosti gastronomske kulture i tradicije kao i promociju različitih poljoprivrednih, prehrambenih i gastronomskih proizvoda. Važno je napomenuti da je većina manifestacija lokalnog karaktera i da značajnijih statističkih pokazatelja o njihovom uticaju na razvoj privrednog sektora nema.

\section{ZAKLJUČAK}

U A.P. Vojvodini se razvoj turizma a time i turizma zasnovanog na kulturi i tradiciji proizvodnje, prerade i pripreme lokalnih jela, i dalje sagledava na osnovu broja ostvarenih turističkih poseta dok se uključenost domicilnog stanovništva privrednih subjekata, zanemaruje. Vojvodina ima veliki potencijal za razradu koncepta održivog turizma zasnovanog na kulturnom nasleđu i tradiciji razvoja, odnosno zasnovanoj na snažnoj sinergiji poljoprivrede i ugostiteljstva. Model koji je poslužio za identifikaciju postojećih resursa, zasnovan na kulturi i tradiciji lokalnih sredina, dobra je baza za sagledavanje postojećeg stanja ali razrada koncepta održivog turizma sa dobrim i temeljnim planiranjem. Ali i primenom odgovarajućih kvalitativnih i kvantitativnih metoda. Principi razvoja moraju biti usaglašeni sa realnim mogućnostima njihove praktične implementacije. U razvoju održivosti u znatnoj meri može doprineti usaglašenost strategija čiji je cilj razvoj privrede regiona zasnovan na tradiciji, kulturi i autentičnosti.

\section{ZAHVALNOST}

Rad je deo projekata broj 142-451-3683/2017-01/02, koji finansiran od strane Pokrajinskog sekretarijata za visoko obrazovanje i naučnoistraživačku delatnost Autonomne pokrajine Vojvodine. 


\section{LITERATURA}

Banjac, M., Tešanović, D., Cvetković, B. (2017). The importance of the relations between agricultural facilities and hospitality facilities for the development of the region tourism. In: 17th Contemporary Trends in Tourism and Hospitalty „New spaces in cultural tourism“. 1-2 September (pp. 67). Novi Sad: Department of Geography, Tourism and Hotel Management.

Banjac, M., Tešanović, D., Cvetković, B. (2017). The importance of the relations between agricultural facilities and hospitality facilities for the development of the region tourism. In: 17th Contemporary Trends in Tourism and Hospitalty „New spaces in cultural tourism“. 1-2 September (pp. 44). Novi Sad: Department of Geography, Tourism and Hotel Management.

Banjac, M., Tešanović, D., Dević Blanuša, J. (2017). Importance of connection between agricultural holding and catering facilities in development of tourism in Vojvodina. In: The Fifth International Academic Conference "Science and Practice of Business Studies" 15th September (pp. 996-1005). Banja Luka: University of Business Studies.

Banjac, M., Tešanović, D., Kalenjuk, B., Nikolić, M., Radivojević, G. (2016). Gastronomic offer of Gornje Podunavlje Special Nature Reserve for the purpose of authentic development of tourism. In: "Monitoring and Management of Visitors in Recreational and Protected Areas" 26-29 September (pp. 503-504). Novi Sad: Department of Geography, Tourism and Hotel Management.

Božin, M. (2018). Salaši za vas : turistički i gastronomski vodič. Novi Sad: Prometej.

Dwyer, L. (2017). Saluting while the ship sinks: The necessity for tourism paradigm change. Journal of Sustainable Tourism, 26(1), 29-48. DOI:10.1080/09669582.2017.1308372.

Getz, R., Robinson, T., Andersson S., \& Vujicic, M. (2014). Foodies and food tourism Goodfellow. Oxford: University of Oxford.

Kalenjuk, B., Čomić, Đ., Tešanović, D., Armenski, T., Škrinjar, M. (2012a). Tourists manifestations in the development of culinary tourism in Vojvodina. In: 21st Biennial International Congress, Tourism \& Hospitality Management, 3 and 5 May (pp 515-526). Opatija: University of Rijeka, Faculty of tourism and hospitality management.

Kalenjuk, B., Tešanović, D., Timotić, M., Banjac, M. (2017). Protected products of animal origin and potentials of protected areas in the function of development of tourism in Vojvodina. In: Trends and challenges in food technology, Nutrition, hospitality, tourism, education and training, Collection proceedings of the 4th International Professional Conference, 19th-20th October (pp.196-204). Ljubljana, Slovenia: Biotechnical Educational Centre Ljubljana.

Kalenjuk, B., Tešanović, D., Gagić, S., Vuksanović, N., \& Škrinjar, M. (2012). Tourism manifestation in the culinary tourism in Banat (Vojvodina, Serbia). Geographica Timisiensis, 2 (1), 22-31.

Kalenjuk, B., Tešanović, D., Korbatfinski, M., Gagić, S., Vuksanović, N., Petrović, M., Ivkov, M. (2012b). Products with origin and their significance for the development of gastronomic tourism in Vojvodina. In: Trends and challenges in food technology, nutrition, hospitality and tourism, 2nd International Professional Conference Proceedings, 16 and 17 November (pp. 349-358). Ljubljana: Turistica.

Kalenjuk, B., Vulić, G., \& Tešanović, D. (2010). Pozicioniranje zaštićenih slovenačkih gastronomski proizvoda u turizmu. Zbornik radova Departmana za geografiju, turizam i hotelijerstvo, 39, 232-247.

Kavaratzis, M., \& Hatch, M.J. (2013). The dynamics of place brands: An identity-based approach to place branding theory. Theory. 13, 69-86. DOI:10.1177/1470593112467268.

Manigodić, M., \& Manigodić, Đ. (2008), Oznake geografskog porekla. Pravni život, 26(13), 5-13.

Pivac, T. (2012). Vinski turizam Vojvodine. Novi Sad: Departman za geografiju turizam i hotelijerstvo (PMF, UNS).

Pollock, A. (2017). Social Entrepreneurship in Tourism. London: Springer.

Rinaldi C. (2017). Food and Gastronomy for Sustainable Place Development: A Multidisciplinary Analysis of Different Theoretical Approaches. Sustainability, 9(10), 17-48. DOI:10.3390/su9101748.

Rogerson, C. M. (2012). Tourism-agriculture linkages in rural South Africa: evidence from the accommodation sector. Journal of Sustainable Tourism, 20(3), 477-495. DOI:10.1080/09669582.2011.617825.

Stojanović, T., \& Čerović, S. (2008). Gastronomic offer of rural tourism: Tourist attraction of geographic area of Serbia. Zbornik radova - Geografski fakultet Univerziteta u Beogradu, 56, 165-176. DOI:338.486:641/642(497.11).

Strategija razvoja poljoprivrede i ruralnih područja 2014-2024. (2014). Sl. glasnik RS”, br. 85/2014. 
Strategiju razvoja turizma Republike Srbije za period od 2016-2025. (2016). Ministarstvo trgovine, turizma i telekomunikacija.

Tešanović, D., Banjac, M., Kalenjuk, B., and Radivojević, G. (2016). The impact of the names of dishes on the guest's choice of restaurant food. In: Singidunum International Tourism Conference 30 September (pp. 169-173). Belgrade: Singidunim University.

Tešanović, D., Kalenjuk, B., Banjac, M. (2108): Sinergija hrane i turizma - uticaj na održivi razvoj regiona. In: VII scientific conference with international participation „Jahorina business forum“ 22-23 March (str. 44-51). Jahorina: Ekonomski fakultet Pale.

Tešanović, D., Kalenjuk, B., Cvetković, B., Tošić, P., Banjac, M. (2017). Gastronomic products of vojvodina in the function ofdevelopment of manifestation tourism. In: The Fifth International Academic Conference "Science and Practice of Business Studies" 15th September (pp. 972-982). Banja Luka: Univerzitet za poslovne studije.

Tešanović, D., Vićić, S., and Kalenjuk, B. (2010). Structure and quality local cuisine in a recognizable serbian regional hospitality facilities. In: The Second International Scientific Expert Conference, Quality and innovation in tourism and catering. 23 and 24 October (pp. 515-526). Bled: Hostel Astoria and Vocational College for Catering and Tourism Bled.

Vuksanović N., Tešanović D., Kalenjuk B., Portić, M., \& Knežević M. (2017). Socio-demographic characteristics as determinants of differences in perception of local gastronomy. Ekonomika poljoprivrede, 1(4), 359-373. DOI:338.48-6:641/642(497.11).

Waligo, V.M., Clarke, J. \& Hawkins, R. (2013). Implementing sustainable tourism: A multi-stakeholder involvement management framework. Tourism Management. 36, 342-353. DOI:10.1016/j.tourman.2012.10.008.

\section{IDENTIFICATION OF GASTRONOMIC RESOURCES AS PART OF THE CULTURAL HERITAGE IN THE DEVELOPMENT OF THE CONCEPT OF SUSTAINABLE DEVELOPMENT OF VOJVODINA}

\begin{abstract}
:
Tourist industry in the northern province of the Republic of Serbia has recorded a growth trend. Its development is generally seen by the number of overnights, while the share of individual entities participating in the creation of tourist products such as local agriculture and restaurant product are less visible. This causes the community and the relevant state entities with their actions to sufficiently encourage the production and use of local food, although it represents a form of cultural capital and resource of economic and social development. The area which has been studied is Vojvodina. The topic of the paper is local food in the tourist offer of the region. The task is to apply the Rinaldi model in order to determine whether all aspects of the identity of the local food community are important for the creation of the concept of sustainable tourism. The aim is the identification of existing resources and highlighting their potential and importance in the development of the region. The study showed that all four Vojvodina located resources have been identified, but that they are not used well enough. Elaboration of the concept of sustainable tourism is not sufficiently recognized in the development of the region.
\end{abstract}

\section{Keywords:}

local food, identification of resources, sustainable tourism 